\section{Histopathologic Evaluation of Radio- Protective Effect of Hesperidin on the Liver of Sprague Dawely Rats}

\author{
Ghorbani Zh. ${ }^{1 \oplus}$, Fardid R..$^{2,3}$, Haddadi G. H. ${ }^{2,3 * \odot}{ }^{\circ}$, Derakh- \\ shanfar A. ${ }^{4}$, Kouhpayeh A. ${ }^{5}$, Haddadi Z. ${ }^{6}$
}

\begin{abstract}
Background: Hesperidin is a bioflavonoid glycoside mainly found in citrus fruit and has been shown radio-protective potential in various measurement systems.

Objective: In this article aims to investigate the radio-protective effect of hesperidin on the liver of Sprague Dawely rats.

Material and Methods: In this clinical study, 40 male rats were selected randomly and divided into 8 groups. Group 1 did not receive radiation and hesperidin (sham control). Group 2 received only $100 \mathrm{mg} / \mathrm{kg}$ body weight (b.w) of hesperidin for 7 consecutive days (HES group); group 3 exposed to dose of 2Gy whole body gamma radiation (2Gy group), and group 4 and 5 received 50 and $100 \mathrm{mg} / \mathrm{kg}$ b.w of HES for 7 consecutive days before 2 Gy gamma radiation, respectively.Group 6 exposed to dose of $8 \mathrm{~Gy}$ gamma radiation (8Gy group); group 7 and 8 received 50 and $100 \mathrm{mg} / \mathrm{kg}$ b.w of HES for 7 days before $8 \mathrm{~Gy}$ gamma irradiation, respectively. Histopathological evaluation was perfomred 24 hours after radiation.

Results: Administration of hesperidin ( $50 \mathrm{mg} / \mathrm{kg}$ b.w, 7 days) before 2Gy of gamma irradiation led to remove inflammatory mononuclear cells in the portal space. Microscopic findings in the groups receiving two doses of hesperidin (50 and 100 $\mathrm{mg} / \mathrm{kg}$ b.w, orally, 7 days), before $8 \mathrm{~Gy}$ of gamma radiation, were similar in a way that extreme dilation of central veins to be seen, however, there was no capillarization.
\end{abstract}

Conclusion: HES can be offered as a suitable radio-protector in radiotherapy patients and radiation workers.

Citation: Ghorbani Zh, Fardid R, Haddadi G. H, Derakhshanfar A, Kouhpayeh A, Haddadi Z. Histopathologic Evaluation of Radio-Protective Effect of Hesperidin on the Liver of Sprague Dawely Rats. J Biomed Phys Eng. 2020;10(1):7-14. doi: 10.31661/jbpe.v0i0.832.

\section{Keywords}

Gamma Rays; Hesperidin; Radio-Protector; Hyperemia; Capillarization

\section{Introduction}

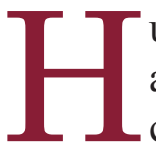
umans are constantly exposed to ionizing radiation from natural and man-made sources such as cosmic rays and medical procedures [1]. Ionizing radiation passing through living tissues produces free radicals such as $\mathrm{O}_{2}^{-*}, \mathrm{H}_{2} \mathrm{O}_{2}, \mathrm{OH}^{\cdot}, \mathrm{NO}_{2}$. The interaction of free radicals with DNA, as critical molecule, can lead to cell damage [2]. Therefore, the use of radio-protector agents with free radical scavenger properties can be useful $[3,4]$.

Earlier, the radio-protective effects of synthetic thiol compounds, including WR- 2721 were considered; however, the inherent toxicity at
${ }^{1} \mathrm{MSc}$, Radiology Department, School of Paramedicine, Shiraz

University of Medical Sci-

ences, Shiraz, Iran

${ }^{2} \mathrm{PhD}$, Radiology De-

partment, School of

Paramedicine, Shiraz

University of Medical Sci-

ences, Shiraz, Iran

${ }^{3} \mathrm{PhD}$, lonizing and

Non-ionizing Radiation

Protection Research

Center (INIRPRC), School

of Paramedicine, Shiraz

University of Medical Sci-

ences, Shiraz, Iran

${ }^{4} \mathrm{PhD}$, Diagnostic

Laboratory Sciences and

Technology Research

Center, Basic Sciences

in Infection Diseases

Research Center, Center

of Comparative \& Experi-

mental Medicine, Shiraz

University of Medical

Sciences, Shiraz, Iran

${ }^{5}$ PhD, Department of

Pharmacology, Fasa

University of Medical Sci-

ence, Fasa, Iran

${ }^{6} \mathrm{MD}$, Medical student,

Student Research Com-

mittee, Fasa University

of Medical Sciences,

Fasa, Iran

*Corresponding author:

G. H. Haddadi

Radiology Department,

School of Paramedi-

cine, Shiraz University

of Medical Sciences,

Shiraz, Iran

E-mail: ghadadi@gmail.

com

Received: 9 September 2017 Accepted: 4 December 2017 
clinically effective doses has restricted their use. Today, the identification of a non-toxic, effective, accessible, inexpensive and preferably the oral administration radio-protective agent has drawn the attention of many researchers to study on the natural compounds [5-9].

Hesperidin (HES), which is one of the most active bioflavonoid, is abundant existing in the skin and membrane parts of lemons and sweat oranges. Hesperidin belongs to the flavanone class of flavonoids family. Molecular formula of hesperidin and molecular weight are $\mathrm{C}_{28} \mathrm{H}_{34} \mathrm{O}_{15}$ and 610.57 Daltons, respectively [10-13].

Hesperidin has a wide range of biological effects, including anti-microbial [14], anti-fungal [15], anti-cancer [16], anti- inflammatory [17], anti-allergic [18], hypolypidemic [19], vaso-protctive [20] and antioxidant effects [21]. Recently, researchers reported that hesperidin possesses radio-protective properties in various measurement systems [22-28]. The study aims to investigate the radio-protective effects of hesperidin on radiation induced hepatotoxicity in male Sprague Dawely rats.

\section{Material and Methods}

\section{Preparation of hesperidin}

In this clinical study, hesperidin (CAS registry number: 520-26- 3) was purchased from $\mathrm{M} / \mathrm{s}$. Sigma Chemical Co, St Louis, USA. The molecular structure of hesperidin (Figure 1) is including flavanone hesperitin and the disac-

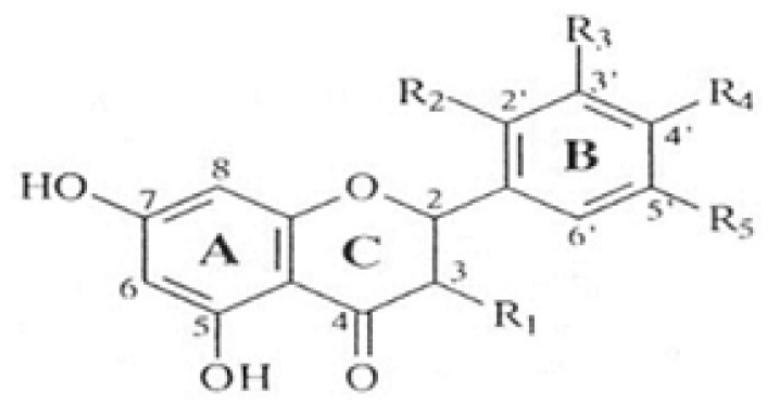

Figure 1: Molecular structure of Hesperidin charide rutinose. Hesperidin was dissolved in Phosphate Buffer Saline (PBS) at two concentrations, including 50 and $100 \mathrm{mg} / \mathrm{kg}$ body weight and administrated to experimental rats once daily for 7 consecutive days orally by ball-tipped needle. The selection seven days for treatment and two concentrations of hesperidin was made according to earlier conducted studies. Hesperidin was prepared freshly every day and administrated sametime throughout the experiment period [29].

\section{Experimental animals}

8-10 week old male Sprague-Dawley rats (180-220 g) purchased from the Center of Comparative and Experimental Medicine, Shiraz University of Medical Sciences were used for the experiments. The rats were housed in accordance with the guideline of the Ethics Committee of Shiraz University of Medical Sciences and given standard pellets diets and water ad libitum.

\section{Irradiation to rats}

One hour after the last dose administration of hesperidin on seventh day, the animals were transferred to the Cobalt 60-gamma irradiator (Theratron 780, Atomic energy of Canada limited, Canada) room. They were anesthetized with an intraperitoneal injection of ketamine $(60 \mathrm{mg} / \mathrm{kg})$ and xylazin $(20 \mathrm{mg} / \mathrm{kg})$ and placed in ventilated plexiglass container. The rats in groups 3, 4 and 5 were exposed to a whole body gamma radiation dose of $2 \mathrm{~Gy}$ while the rats in groups 6, 7 and 8 were exposed to a whole body gamma irradiation dose of $8 \mathrm{~Gy}$. The source-to-skin distance was $80 \mathrm{~cm}$ with a dose rate of $30 \mathrm{cGy} / \mathrm{min}$ and field size of $35 \times 30 \mathrm{~cm}^{2}$.

\section{Experimental groups}

After seven days acclimation to laboratory conditions, rats were randomly divided into 8 groups with 5 animals in each ( $\mathrm{n}=5$ per cage). Group 1 did not receive radiation and hesperidin (sham control). Group 2 received only 100 
Hesperidin as a Radio - Protector

$\mathrm{mg} / \mathrm{kg}$ body weight of hesperidin for 7 consecutive days (HES group), and group 3 exposed to dose of $2 \mathrm{~Gy}$ whole body gamma radiation (2Gy group); groups 4 and 5 received 50 and $100 \mathrm{mg} / \mathrm{kg}$ b.w of HES for 7 consecutive days before $2 \mathrm{~Gy}$ whole body gamma irradiation, respectively (50 mg/kg b.w HES + 2Gy, $100 \mathrm{mg} /$ kg b.w HES + 2Gy groups). Group 6 exposed to dose of $8 \mathrm{~Gy}$ whole body gamma radiation (8Gy group). Group 7 and 8 received 50 and $100 \mathrm{mg} / \mathrm{kg}$ b.w of HES for 7 consecutive days before 8 Gy whole body gamma irradiation, respectively (50 mg/kg b.w HES + 8Gy, 100 $\mathrm{mg} / \mathrm{kg}$ b.w HES +8 Gy groups). The sham control and only radiation groups received phosphate buffer saline for 7 consecutive days via gavage before whole body gamma irradiation.

\section{Histopathological examinations}

Twenty four hours after exposure to gamma radiation, the animals were euthanized with ether and livers were removed and minced into small pieces. The small pieces of liver were fixed in $10 \%$ buffered formalin and washed and also dehydrated in an ascending series of alcohols. Next, they were embedded in paraffin wax, and then multiple section from liver in 5 micron thickness were prepared and stained with hematoxylin and eosin $(\mathrm{H} \&$ E). Histopathological changes of the liver in above-mentioned groups were evaluated by light microscope.

\section{Results}

Hepatic histopathological findings in experimental groups are summarized in the Table 1.

Histopathological observations showed normal liver tissue in the control group (Figure 2A). In the hesperidin group, hyperemia was observed in the normal structure of the liver (Figure 2B). Exposure to 2Gy of gamma radiation led to accumulating inflammatory mononuclear cells in the portal space and central vein dilation (Figure 2C and D). Severe central vein dilation and capillarization of sinusoids were seen in exposure to 8Gy of gamma radiation (Figure $2 \mathrm{G}$ and $\mathrm{H}$ ). Oral administration of hesperidin $(50 \mathrm{mg} / \mathrm{kg}$ b.w, orally, 7 days $)$ before 2Gy of gamma (Figure 2E ) irradiation led to removing inflammatory mononuclear cells from the portal space; however, there was still central vein dilation, and hesperidin, at a dose of $100 \mathrm{mg} / \mathrm{kg}$ before $2 \mathrm{~Gy}$ of gamma irradiation (Figure 2F), was observed by natural liver structure. Microscopic findings in the

Table 1: Histopathological changes in the liver tissue in eight groups after gamma irradiation

\begin{tabular}{|c|c|c|c|c|}
\hline Lesion & Hyperemia & $\begin{array}{c}\text { Dilation of central } \\
\text { veins }\end{array}$ & $\begin{array}{c}\text { inflammatory } \\
\text { mononuclear cells }\end{array}$ & Capillarization \\
\hline Sham control & - & - & - & - \\
\hline $2 G y$ & - & + & + & - \\
\hline $50 \mathrm{mg} / \mathrm{kg} \mathrm{HES}+2 \mathrm{~Gy}$ & - & + & - & - \\
\hline $100 \mathrm{mg} / \mathrm{kg} \mathrm{HES}+2 \mathrm{~Gy}$ & - & - & - & - \\
\hline 8Gy & - & ++ & - & ++ \\
\hline 50 m/kg HES+8Gy & - & ++ & - & - \\
\hline 100 mg/kg HES+8Gy & - & ++ & - & - \\
\hline HES & + & - & - & - \\
\hline
\end{tabular}

$(-)$ absent, $(+)$ mild, $(++)$ severe, rats were administrated with two concentration of hesperidin for 7 consecutive days before $2 \mathrm{~Gy}$ of gamma irradiation. Histopathological damages were assessed as explained under materials and methods. 

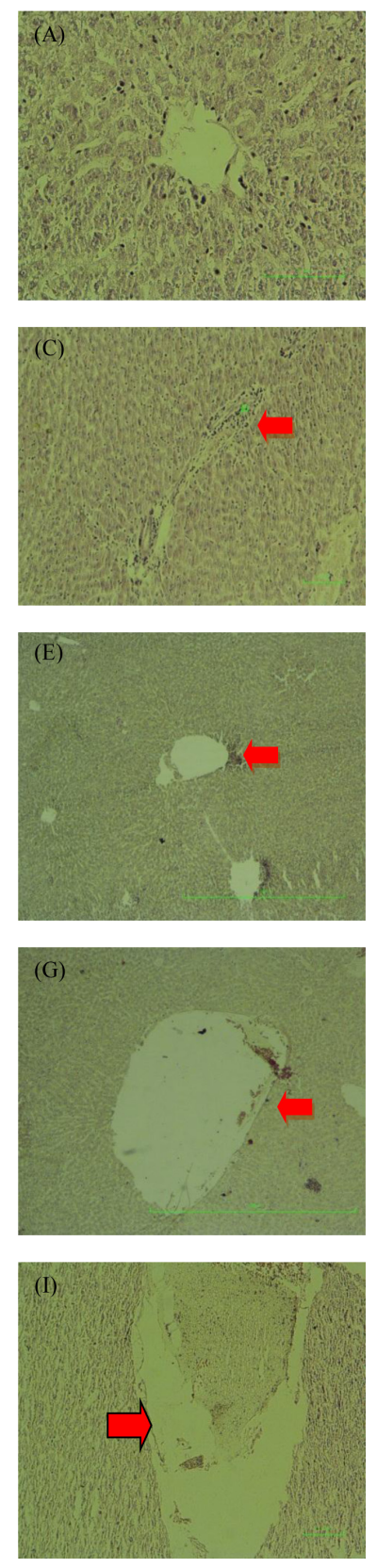
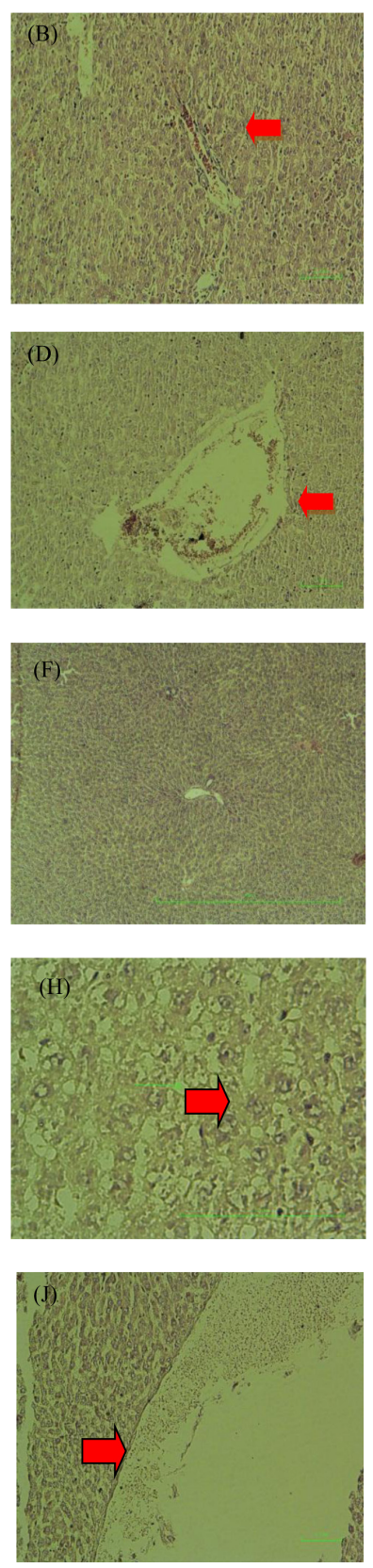

Figure 2: Effects of radiation, hesperidin and hesperidin plus radiation on liver tissue of rats stained with $H$ \& E. (A); Liver sections of normal rat showing normal hepatocytes (x200). (B); liver sections of the rats administered by HES $(100 \mathrm{mg} / \mathrm{kg})$ showing heperemia (x200). (C \& D); liver sections of the rats exposed with $2 \mathrm{~Gy}$ of gamma radiation showing inflammation and dilation of central vein (x100). (E); liver section of the rats administered by HES(50 mg/ $\mathrm{kg}$ ) before $2 \mathrm{~Gy}$ of gamma radiation showing dilation of central vein $(\mathrm{x} 40)$. (F); liver sections of the rats administered by HES (100 $\mathrm{mg} / \mathrm{kg}$ ) before $2 \mathrm{~Gy}$ of gamma radiation showing nearly normal liver structure (x200). (G \& H); liver sections of the rats exposed with $86 y$ of gamma radiation showing severe dilation of central veins and capillarization of sinusoids ( $x 400)$. (I); liver section of the rats administered by HES $(50 \mathrm{mg} / \mathrm{kg}$ ) before $8 \mathrm{~Gy}$ of gamma radiation showing severe dilation of central vein (x100). (J); liver section of the rats administered by HES (100 mg/kg) before $8 \mathrm{~Gy}$ of gamma radiation showing severe dilation of central vein $(x 100)$. 
groups receiving two doses (50 and $100 \mathrm{mg} /$ $\mathrm{kg}$ b.w, orally, 7 days) before $8 \mathrm{~Gy}$ of gamma radiation were similar, in a way that extreme dilation of central veins to be seen but there was no capillarization (Figure 2L and J).

\section{Discussion}

Radiation therapy plays an important role in the treatment of hepatic tumors. The radiation tolerance of liver is rather limited. The effect of radiation on non tumor compartment of liver is one of the most important dose-limiting factors resulting in simultaneous liver cirrhosis. This is a major challenge in radiotherapy that often greatly impairs the quality life of the affected patients [30]. Several studies have shown that hesperidin can improve radiationinduced damage in various tissues, including liver [23], heart [31], kidney, spleen [26], brain [28], blood, lung, skin [32]. In the experiments conducted on animal models using hesperidin administration at different doses of hesperidin administrated orally (or intraperitoneal) before (or after) to gamma radiation with different doses [21]. The results of our study showed that exposure to $2 \mathrm{~Gy}$ of gamma radiation led to accumulation of inflammatory mononuclear cells in the portal space and dilation of central veins. Oral administration by hesperidin at dose of $50 \mathrm{mg} / \mathrm{kg}$ b.w for seven consecutive days, before whole body gamma irradiation dose of $2 \mathrm{~Gy}$, led to removing inflammatory mononuclear cells in the portal space in comparison with gamma irradiation dose of 2 Gy only. Oral administration by hesperidin at dose $100 \mathrm{mg} / \mathrm{kg}$ b.w for 7 consecutive days before whole body gamma irradiation of $2 \mathrm{~Gy}$ prevents from radiation- induced damage in liver in comparison with $2 \mathrm{~Gy}$ of gamma radiation. Histopathological data showed that exposure to 8Gy of gamma irradiation led to severe dilation of central veins and sinusoid capillarization.

Microscopic findings were similar in groups 50 and $100 \mathrm{mg} / \mathrm{kg}$ b.w hesperidin before 8Gy of gamma radiation and central vein dilation was seen. Said et al. reported that whole body exposure of rats to 7 Gy gamma radiation resulted in loss of normal hepatic architecture, extremely dilated hepatic portal vein and hemorrhage, inflammatory cells and fibroblasts surrounding the portal vein and dilated sinusoids [33]. In addition, Rady et al. found that the most remarkable changes after gamma irradiation are the loss normal hepatic architecture, dilation and congestion in blood vessels and appearance of inflammatory cells [34].

The results of the Kalpana and Pradeep studies agreed with our results. They showed that hesperidin possess antioxidant and free radical scavenging properties. Free radical scavenging properties of HES are due to hydroxyl groups in aromatic structure of HES. HES can give hydrogen atom from their hydroxyl groups to unpaired electrons [35, 36]. Therefore, HES can suppressed DNA damage made by produced free radicals stemmed from ionizing radiation. In addition, hesperidin can directly react with DNA molecules and lead to a protective effect [37].

According to the results obtained in this study, oral administration of HES $(100 \mathrm{mg} / \mathrm{kg}$ b.w/day) before exposure to whole body gamma radiation, especially for $2 \mathrm{~Gy}$ of gamma radiation, prevented from radiation damage in liver by ameliorating the dilation of central veins, capillarization of sinusoids and presence of inflammatory mononuclear cells.

\section{Conclusion}

Based on the finding in this study, it reveals that Hesperidin would improve the radiationinduced damage. Therefore, HES may be offered as a suitable radio-protector in radiotherapy patients, radiation workers and public.

\section{Acknowledgment}

The authors would like to thank Aboozar Valizadeh for his kind cooperation in tissue slide preparation and Mohammad Haidari for performing the animal experiments. This work was supported by the Shiraz University of 
Ghorbani Zh., Fardid R., Haddadi G. H. et al

Medical Sciences for the accomplishment of the research project of Gholamhassan Haddadi and Zhila Ghorbani (Grant number: 10408).

\section{Conflict of Interest}

None

\section{References}

1. Meister KA, Karam PA. The Health Effects of Low Level Radiation. New York: American Council on Science and Health; 2005.

2. Riley PA. Free radicals in biology: oxidative stress and the effects of ionizing radiation. Int $J$ Radiat Biol. 1994;65:27-33. PubMed PMID: 7905906. doi: 10.1080/09553009414550041.

3. Bhosle SM, Huilgol NG, Mishra KP. Enhancement of radiation-induced oxidative stress and cytotoxicity in tumor cells by ellagic acid. Clin Chim Acta. 2005;359:89-100. doi: 10.1016/j. cccn.2005.03.037. PubMed PMID: 15922998.

4. Weiss JF, Landauer MR. Radioprotection by antioxidants. Ann N Y Acad Sci. 2000;899:44-60. PubMed PMID: 10863528.

5. Hosseinimehr SJ. Trends in the development of radioprotective agents. Drug Discov Today. 2007;12:794-805. doi: 10.1016/j. drudis.2007.07.017. PubMed PMID: 17933679.

6. Citrin D, Cotrim AP, Hyodo F, Baum BJ, Krishna MC, Mitchell JB. Radioprotectors and mitigators of radiation-induced normal tissue injury. Oncologist. 2010;15:360-71. doi: 10.1634/theoncologist.2009-S104. PubMed PMID: 20413641. PubMed Central PMCID: PMC3076305.

7. Abbaszadeh A, Haddadi GH, Haddadi Z. Melatonin Role in Ameliorating Radiation-induced Skin Damage: From Theory to Practice (A Review of Literature). J Biomed Phys Eng. 2017;7:12736. PubMed PMID: 28580334. PubMed Central PMCID: PMC5447249.

8. Rezaeyan A, Fardid R, Haddadi GH, Takhshid MA, Hosseinzadeh M, Najafi M, et al. Evaluating Radioprotective Effect of Hesperidin on Acute Radiation Damage in the Lung Tissue of Rats. J Biomed Phys Eng. 2016;6:165-74. PubMed PMID: 27853724. PubMed Central PMCID: PMC5106549.

9. Shirazi A, Haddadi GH, Ghazi-Khansari M, Abolhassani F, Mahdavi SR, Eshraghyan MR. Evaluation of melatonin for prevention of radiation myelopathy in irradiated cervical spinal cord.
Cell J. 2009;11:43-8

10. Garg A, Garg S, Zaneveld LJ, Singla AK. Chemistry and pharmacology of the Citrus bioflavonoid hesperidin. Phytother Res. 2001;15:65569. doi: 10.1002/ptr.1074. PubMed PMID: 11746857.

11. Montanari A, Chen J, Widmer W. Citrus flavonoids: a review of past biological activity against disease. In Flavonoids in the living system. Manthey and Buslig, editors. New York: Plenum Press; 1998:103-16. doi: 10.1007/9781-4615-5335-9_8. PubMed PMID: 9781298.

12. Middleton EJ. Effect of plant flavonoids on immune and inflammatory cell function. Adv Exp Med Biol. 1998;439:175-82. doi: 10.1007/9781-4615-5335-9_13. PubMed PMID: 9781303.

13. Emim JA, Oliveira AB, Lapa AJ. Pharmacological evaluation of the anti-inflammatory activity of a citrus bioflavonoid, hesperidin and the isoflavonoids, duartin and claussequinone, in rats and mice. J Pharm Pharmacol. 1994;46:11822. doi: 10.1111/j.2042-7158.1994.tb03753.x. PubMed PMID: 8021799.

14.Cushnie TP, Lamb AJ. Antimicrobial activity of flavonoids. Int $J$ Antimicrob Agents. 2005;26:343-56. doi:10.1016/j.ijantimicag.2005.09.002. PubMed PMID: 16323269.

15. Krolicki Z, Lamer-Zarawska E. Investigation of antifungal effect of flavonoids. 1 [hesperidin, naringin, phellodendroside, luteolin-7-glucoside, hipotethin-7-glucoside, quecetin, celastroside, amentoflavone; Botrytis cinerea, Trichoderma glaucum, Aspergillus fumigatus]. Herba Polonica (Poland). 1984.

16. Ahmadi A, Shadboorestan A. Oxidative stress and cancer; the role of hesperidin, a citrus natural bioflavonoid, as a cancer chemoprotective agent. Nutr Cancer. 2016;68:29-39. doi: 10.1080/01635581.2015.1078822. PubMed PMID: 26381129.

17. Dalgard C, Nielsen F, Morrow JD, EnghusenPoulsen $H$, Jonung $T$, Horder $M$, et al. Supplementation with orange and blackcurrant juice, but not vitamin $E$, improves inflammatory markers in patients with peripheral arterial disease. $\mathrm{Br} J$ Nutr. 2009;101:263-9. doi: 10.1017/S0007114508995660. PubMed PMID: 18507878.

18. Lee NK, Choi SH, Park SH, Park EK, Kim $\mathrm{DH}$. Antiallergic activity of hesperidin is activated by intestinal microflora. Pharmacology. 
Hesperidin as a Radio - Protector

2004;71:174-80. doi: 10.1159/000078083. PubMed PMID: 15240993.

19. Monforte MT, Trovato A, Kirjavainen S, Forestieri AM, Galati EM, Lo Curto RB. Biological effects of hesperidin, a Citrus flavonoid. (note II): hypolipidemic activity on experimental hypercholesterolemia in rat. Farmaco. 1995;50:5959. PubMed PMID: 7495469.

20. Kumar B, Gupta SK, Srinivasan BP, Nag TC, Srivastava S, Saxena R. Hesperetin ameliorates hyperglycemia induced retinal vasculopathy via anti-angiogenic effects in experimental diabetic rats. Vascul Pharmacol. 2012;57:201-7. doi: 10.1016/j.vph.2012.02.007. PubMed PMID: 22967957.

21. Kuntic V, Brboric J, Holclajtner-Antunovic I, Uskokovic-Markovic S. Evaluating the bioactive effects of flavonoid hesperidin--a new literature data survey. Vojnosanit Pregl. 2014;71:60-5. doi: 10.2298/vsp1401060k. PubMed PMID: 24516992.

22. Kalpana KB, Devipriya N, Srinivasan M, Menon VP. Investigation of the radioprotective efficacy of hesperidin against gamma-radiation induced cellular damage in cultured human peripheral blood lymphocytes. Mutat Res. 2009;676:5461. doi: 10.1016/j.mrgentox.2009.03.005. PubMed PMID: 19486865.

23. Kalpana KB, Devipriya N, Srinivasan M, Vishwanathan P, Thayalan K, Menon VP. Evaluating the radioprotective effect of hesperidin in the liver of Swiss albino mice. Eur J Pharmacol. 2011;658:206-12. doi: 10.1016/j. ejphar.2011.02.031. PubMed PMID: 21371459.

24. Fardid R, Ghorbani Z, Haddadi G, BehzadBehbahani A, Arabsolghar R, Kazemi E, et al. Effects of Hesperidin as a Radio-protector on Apoptosis in Rat Peripheral Blood Lymphocytes after Gamma Radiation. J Biomed Phys Eng. 2016;6:217-28. PubMed PMID: 28144590. PubMed PMCID: PMC5219572.

25. Ahmadi A, Hosseinimehr SJ, Naghshvar F, Hajir E, Ghahremani M. Chemoprotective effects of hesperidin against genotoxicity induced by cyclophosphamide in mice bone marrow cells. Arch Pharm Res. 2008;31:794-7. doi: 10.1007/ s12272-001-1228-z. PubMed PMID: 18563363.

26. Pradeep K, Ko KC, Choi MH, Kang JA, Chung YJ, Park SH. Protective effect of hesperidin, a citrus flavanoglycone, against $\gamma$-radiationinduced tissue damage in Sprague-Dawley rats. J Med Food. 2012;15:419-27. doi: 10.1089/ jmf.2011.1737.

27. Pradeep K, Park SH, Ko KC. Hesperidin a flavanoglycone protects against gamma-irradiation induced hepatocellular damage and oxidative stress in Sprague-Dawley rats. Eur $J$ Pharmacol. 2008;587:273-80. doi: 10.1016/j. ejphar.2008.03.052. PubMed PMID: 18485345.

28. Said UZ, Saada HN, Abd-Alla MS, Elsayed ME, Amin AM. Hesperidin attenuates brain biochemical changes of irradiated rats. Int J Radiat Biol. 2012;88:613-8. doi: 10.3109/09553002.2012.694008. PubMed PMID: 22671307.

29. Kumar A, Ram J, Samarth RM, Kumar M. Modulatory influence of Adhatoda vasica Nees leaf extract against gamma irradiation in Swiss albino mice. Phytomedicine. 2005;12:285-93. doi: 10.1016/j.phymed.2003.12.006. PubMed PMID: 15898706.

30.Liang SX, Zhu XD, Xu ZY, Zhu J, Zhao JD, Lu $\mathrm{HJ}$, et al. Radiation-induced liver disease in three-dimensional conformal radiation therapy for primary liver carcinoma: the risk factors and hepatic radiation tolerance. Int J Radiat Oncol Biol Phys. 2006;65:426-34. doi: 10.1016/j. ijrobp.2005.12.031. PubMed PMID: 16690430.

31. Pradeep K, Ko KC, Choi MH, Kang JA, Chung YJ, Park SH. Protective effect of hesperidin, a citrus flavanoglycone, against $\gamma$-radiationinduced tissue damage in Sprague-Dawley rats. J Med Food. 2012;15:419-27. doi: 10.1089/ jmf.2011.1737.

32. Jagetia G, Mallikarjuna Rao K. Hesperidin, a citrus bioflavonoid reduces the oxidative stress in the skin of mouse exposed to partial body $\gamma$-radiation. Transcriptomics. 2015;3:2. doi: 10.4172/2329-8936.1000111.

33. Said U, Saada H, Rezk R. Role of calcium pantothenate in recovery of radiation induced injury to mammalian organs. Egyptian Journal of Radiation Sciences and Applications. 2005;18:1738.

34. Rady M, Abu N, Khalii I. Effect of Gamma Radiation on the Albino Rat's Liver and the Possible Protective Role of $\beta$-carotene on the Histological and Ultra Structural Changes. Egyptian Journal of Radiation Sciences and Applications. 2008;21:373-88.

35. Dillard CJ, German JB. Phytochemicals: nutraceuticals and human health. $J$ Sci Food Agric. 2000;80:1744-56. 
Ghorbani Zh., Fardid R., Haddadi G. H. et al

36. Choi CW, Kim SC, Hwang SS, Choi BK, Ahn HJ, Lee MY, et al. Antioxidant activity and free radical scavenging capacity between Korean medicinal plants and flavonoids by assay-guided comparison. Plant Sci. 2002;163:1161-8. doi: 10.1016/s0168-9452(02)00332-1.

37. Yoshikawa Y, Suzuki M, Yamada N, Yoshikawa K. Double-strand break of giant DNA: protection by glucosyl-hesperidin as evidenced through direct observation on individual DNA molecules. FEBS Lett. 2004;566:39-42. doi: 10.1016/j.febslet.2004.04.008. PubMed PMID: 15147865. 